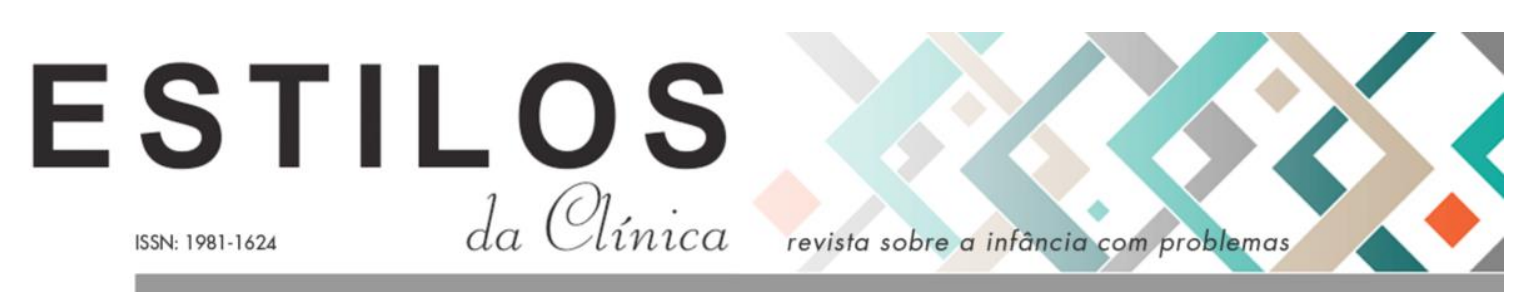

DOI: https://doi.org/10.11606/issn.1981-1624.v24i3p384-392.

\title{
Dossiê
}

\section{Quem serão os autistas de amanhã?}

\author{
Maria Cristina Machado Kupfer
}

Resumo. Para responder, da perspectiva da psicanálise, à pergunta sobre quem serão os autistas de amanhã, busca-se, em primeiro lugar, traçar linhas de como se encontram os autistas no passado. Durante o século XIX, olhar médico não podia ainda diferenciar os débeis das crianças que já estavam provavelmente desenvolvendo aquilo que hoje chamamos de autismo. Mas ouvimos seus ecos em relatos de autores da época. Para refletir sobre o momento presente, apela-se para dois operadores conceituais: o discurso e a genética, concluindo que esse novo modo de ser autista combina hoje com as novas formas de dessubjetivação que estão surgindo. O presente revela ainda que as crianças autistas, escolarizadas pelos métodos comportamentais, perdem a chance de viver na escola a verdade de sua experiência, uma experiência peculiar e única. Perdem a chance de aprender a se dizer. Em relação ao futuro, afirmase que são muitos os devires dos autistas. Mas haverá um ponto comum a todos eles: neles o sujeito freudiano não estará, em consonância com a supressão do sujeito no mundo contemporâneo.

Palavras-chave: autismo; psicanálise; dessubjetivação; sujeito freudiano.

\section{¿Quiénes serán los autistas del mañana?}

Resumen. Para responder, desde la perspectiva del psicoanálisis, la pregunta de quiénes serán los autistas del mañana, primero buscamos trazar líneas de cómo las personas autistas son en el pasado. Durante el siglo XIX, el ojo médico aún no podía diferenciar a los débiles de los niños que probablemente ya estaban desarrollando lo que ahora llamamos autismo. Pero escuchamos sus ecos en los informes de los autores de la época. Para reflexionar sobre el momento presente, recurrimos a dos operadores conceptuales: el discurso y la genética, concluyendo que esta nueva forma de ser autista se combina hoy con las nuevas formas de desubjetivación que están surgiendo. El presente también revela que los niños autistas, educados por métodos de comportamiento, pierden la oportunidad de vivir en la escuela la verdad de su experiencia, una experiencia peculiar y única. Pierden la oportunidad de aprender a decirse a sí mismos. Con respecto al futuro, se dice que hay muchos devires de autistas. Pero habrá un punto en común para todos ellos: en ellos el sujeto freudiano no estará presente, en línea con la supresión del sujeto en el mundo contemporáneo.

Palabras-clave: autismo; psicoanálisis; desubjetivación; sujeto freudiano.

* Professora Titular Sênior da Universidade de São Paulo, São Paulo, SP, Brasil. E-mail:mckupfer@usp.br 


\title{
Who will be the autists of tomorrow?
}

\begin{abstract}
To answer, from the perspective of psychoanalysis, the question of who will be the autists of tomorrow, we first seek to draw lines of how autistic people are in the past. During the nineteenth century, the medical eye could not yet differentiate children with disabilities from children who were probably already developing what we now call autism. But we hear their echoes in reports by authors of that time. To reflect on the present moment, we appeal to two conceptual operators: discourse and genetics, concluding that this new way of being autistic combines today with the new forms of desubjectivation that are emerging. The present times also reveals that autistic children, educated by behavioral methods, lose the chance to live in school the truth of their experience, a peculiar and unique experience. They lose the chance to learn to say about themselves. Regarding the future, it is said that there are many becomings of autists. But there will be a common point to all of them: in them the Freudian subject will not be present, in line with the suppression of the subject in the contemporary world.
\end{abstract}

Keywords: autismo; psychoanalysis; desubjectivation; freudian subject.

\section{Que crianças deixaremos para amanhã? Quem serão os autistas de amanhã?}

Para uma boa parcela de psicanalistas, falar de futuro não passe de especulação. Essa parcela problematiza, por exemplo, a noção de detecção precoce, de previsão ou, pior ainda, de uma predição, o que coloca os psicanalistas de bebês em uma posição incômoda. Nessa polêmica, os mais sensatos pedem aos psicanalistas de bebês que pensem apenas no sofrimento psíquico, noção, diga-se de passagem, pouco psicanalítica, e que não se aventurem a olhar para o futuro, já que ele dependerá de acontecimentos imprevisíveis e capazes de mudar o curso da vida do bebê. Argumentam também que nada se pode dizer do tempo 1 se não houver o tempo 2, que dará sentido ao tempo 1.

Sejamos freudianos. É Freud quem reflete sobre o Futuro de uma ilusão. É ele que especula sobre a pulsão de morte, mas escreveu, a partir dessa especulação, uma das formulações mais importantes da psicanálise. Ou seja, especular é preciso, contanto que tenhamos sido inspirados por aquilo que se ouve e se recolhe anos a fio na clínica.

Sejamos sensatos: a psicanálise não opera com evidências; estamos comprometidos com uma epistemologia do inconsciente e com a escuta do que se lê no que se diz, como diz Lacan (1957/1978), e não com o que se vê. Mas a ciência das evidências - que mata esse sujeito, ok mostra, além disso, regularidades. E as regularidades mostram uma direção para a qual apontam populações. As regularidades mostram, por exemplo, que o irmão de uma criança autista tem muita mais chances de desenvolver autismo do que outra criança; mostram que na familia de uma criança autista há inúmeros parentes com autismo. Se um clínico sabe disso, fruto da experiência de uma cultura, pode ele ignorar esse conhecimento? Um psicanalista encontra um bebê com sinais que os estudos sobre as regularidades apontam ser encontrados em crianças futuros autistas. Mas esse bebê não exibe sinais de sofrimento - nem ele nem os pais - ; então, deve deixa-los ir, já que não há 
sequer demanda? Deve o psicanalista, além disso, dar as costas à discussão sobre políticas públicas, já que as políticas trabalham com populações e não com o singular?

Ainda que deva deixar em meu consultório meus instrumentos de trabalho, vou conversar com gestores de politicas públicas. Lá tenho que falar de evidências, tenho que falar de previsão, de risco, tenho que adotar o vocabulario médico e lembrar que ali se trabalha com populações, uma realidade muito distante daquela de meu consultório particular.

Por essas razões, aceito especular sobre o futuro, ainda que essa seja uma tarefa extremamente ambiciosa.

Para falar do futuro das crianças autistas, temos que falar antes de seu passado, para ver para onde apontam nossos dados, que, a partir da experiência acumulada, criam então um vetor, uma direção que se descortina e realizar assim uma espécie de projeção, orientada pela pergunta: quem serão os autistas de amanhã?

\section{O passado}

Já se sabe que os primeiros autistas de que se tem notícia emergiram da grande massa dos idiotas que surgiram no cenário da recém nascida psiquiatria, no início do século XIX, com Pinel (1801) e seu Tratado médico-filosófico sobre a alienação mental ou a mania.

O olhar médico não podia ainda diferenciar os débeis das crianças que já estavam provavelmente desenvolvendo, na aurora do século XIX, aquilo que hoje chamamos de autismo. Não havia lentes para vê-los. Mas ouvimos seus ecos em relatos como os que Hochmann (2009) destaca, por exemplo. Podemos hoje olhar os arquivos de fotos de crianças ditas idiotas examinadas em Bicêtre por Bourneville (1893) no fim do século XIX, arquivos esses hoje disponíveis na Internet. Nesses arquivos, pode-se hoje talvez dizer que muitos tinham o que chamamos hoje de autismo.

É o que mostra Séguin já em 1846 (Seguin, 1846). Os idiotas que ele estuda balançam-se, elegem objetos que eles sacodem diante dos olhos, não fixam o olhar, agitam os dedos diante dos olhos, estão submetidos ao desmantelamento de Meltzer (1980), como diz Hochmann (2009).

As crianças nascidas com as condições colocadas para desenvolver um autismo acabavam, talvez, por ser abandonadas pelos pais, que desistiam de falar com eles ao não obter respostas de seus filhos.

Havia, talvez, muito mais Victors de Aveyron que se supõe hoje, mas ninguém olhava para um bebê procurando sinais de desconexão, e as crianças só chegavam a Bicêtre com a chamada idiotia instalada. (Observação de passagem: buscar os sinais hoje é patologizar ou prevenir?)

Assim, temos duas direções de reflexão: ou bem as crianças ditas idiotas já eram autistas em boa parte, ou eram pouco numerosas mas foram se multiplicando com o passar do tempo. Seja qual for a direção tomada, o fato é que hoje constata-se um número significativo de crianças com autismo. 


\section{O momento presente}

Sempre que falo de autismo, costumo dizer que sua escalada no mundo contemporâneo se deu porque, em primeiro lugar, houve uma modificação dos critérios diagnósticos, mas também porque aumentaram os diagnósticos corretos, porque há uma epidemia diagnóstica e porque houve um aumento real. Sobre essa última constatação, porém, não discorro muito longamente, embora ela seja ancorada em minha experiência clínica de alguns anos.

Em 2000, escrevi: “a sociedade moderna vê no autista a denúncia de sua falha, a denúncia do modo como está tratando suas crias. Choca mais do que a infância abandonada, embora a balança numérica penda muito mais para o lado dos meninos de rua do que para o lado dos autistas" (Kupfer, 2000, p. 101). Quase vinte anos depois, sou obrigada a rever esse comentário. Se não olharmos para dentro dos lares em que pais vivem as enormes dificuldades para criar uma criança autista, veremos um cenário que mudou muito: hoje o número pende para os autistas, o autismo não denuncia mais nada e não choca mais ninguém: criou-se o orgulho autista, e o esforço das associações de pais de autistas vai na direção de afirmar uma identidade autista, um modo de ser.

A cultura contemporânea os absorveu. Foram consumidos pelo capitalismo. Mas não estão de modo algum consumados. Ao contrário: multiplicam-se?

Para refletir sobre esse momento presente, em busca de suas origens, poderíamos apelar para dois operadores conceituais: o discurso e a genética.

$\mathrm{O}$ autismo, como efeito discursivo, poderia equiparar-se ao efeito que colhemos quando acompanhamos o fenômeno de contaminação que podemos chamar de "Columbine"? Como um rastilho de pólvora, os jovens americanos matam em série seus colegas nas escolas. Ouvem dizer nos noticiários, nos filmes, deixam-se afetar pelos discursos em circulação e pelas promessas de gozos não socializados que eles portam, pelo paroxismo de gozo imbuído na morte dos outros e na própria morte, em tempos nos quais a vacuidade da vida faz dela um bem pouco atraente. São jovens para quem o amor e a sexualidade não fazem mais sentido, e nisso talvez estejam próximos dos autistas. Como diz Askofaré (2009), está em jogo a forclusão do sexo e do amor.

Mas o autismo é mais do que um comportamento. A psicanálise ouve discursos, mas as determinações do Real lhe escapam, e talvez seja preciso ir à Biologia para constatar uma espécie de transmissão entre gerações. Constata-se na clínica que uma criança autista nasce em uma família cujo pai pode ser considerado, hoje em um diagnóstico retroativo, um autista leve em sua infância. Estaria uma alteração genética sendo transmitida?

Para Gonon (2015), a epigenética pesquisa os mecanismos moleculares que explicam que um fator ambiental possa acarretar modificações profundas, duráveis e até transmissíveis à geração seguinte na atividade gênica!

Porém, o interesse dos estudos genéticos e epigenéticos não está em sua "verdade científica", mas naquilo para que aponta: os autistas parecem ser bem adaptativos, em um sentido darwiniano, aos tempos de dessubjetivação ou de assubjetivação contemporâneos. 
Com os autistas, está surgindo uma nova forma de estar no mundo, para a qual não se pode nem dizer que é uma nova forma de subjetivação, já que o sujeito, na acepção psicanalítica do termo sujeito do inconsciente, sujeito do desejo, criança edípica - está ausente. Esse novo modo de ser autista combina maravilhosamente com as novas formas de dessubjetivação que estão surgindo, apontadas por exemplo por autores como Dufour (2005), em A arte de reduzir as cabeças.

Para aquele autor, o sujeito pós-moderno, uma nova forma de assubjetivação, é um sucedâneo da lógica capitalista. Esse sujeito pós-moderno se instalou depois que foram destruídos o sujeito crítico (kantiano) e o sujeito neurótico (freudiano), e particularmente o edípico. Para Dufour (2005), o sujeito pós-moderno não teve apenas seu corpo consumido pelo capitalismo; é seu espírito aquilo que está sendo consumido agora. É à redução dos espíritos, à redução das cabeças, que assistimos hoje.

Ora, nosso autista também sofre uma redução em sua robotização. O comportamentalismo também combina muito bem com essa redução que leva à supressão do sujeito.

Dufour (2005) aproxima esse sujeito que está nascendo com uma psicotização, e isso por dois motivos: porque ele é fruto de uma dessimbolização - ou de uma alteração no simbólico - e porque em seu cerne instalou-se um vazio, ambos fruto do capitalismo. Ora, esses dois movimentos aproximam o sujeito pós-moderno muito mais do autista do que do psicótico. É o autista que opera com o signo, é ele que se encontra "limpo de gozo".

O autista convive bem também com o que Dufour chama de negação da diferença sexual e do complexo de Édipo, noção que organiza essa diferença. Pois também a criança autista "nega" o Édipo, já que ela está aquém do Édipo. Essa criança também convive bem com a reprodução em laboratório, e também com um desinteresse pela sexualidadade que cresce entre os jovens europeus, já que a criança autista não pulsionalizada não se transformará em um adulto interessado no prazer compartilhado.

O autismo também está em consonância com os tempos da supressão do sujeito perpretados pela Ciência e pela Medicina Moderna. Por que seu gosto pela máquina, pelos ventiladores, pelos computadores? Porque na máquina o sujeito não está: foi suprimido. A máquina não demanda nada. Ao contrário, repete sempre de mesmo modo e não o surpreende nunca, a não ser quando quebra. O autista estará sempre fazendo uma evitação ativa de qualquer situação em que haja rastro de sujeito no outro: recusará, tapando seus ouvidos, não a voz dos outros, mas seu timbre de voz (Catão e Vivès, 2011), que também carrega o traço e o rastro do sujeito em sua enunciação insuportável.

O autista não suporta a enunciação. No mundo sem limites, de Lebrun (2004), a Ciência de hoje se sustenta apenas com "os enunciados, que visam fazer desaparecer a enunciação". Para Lebrun, "o dito visa apagar o dizer, e o saber, que vale para todos, visa apagar a verdade singular". Assim, também na supressão da enunciação o autista converge com o discurso da Ciência. 


\section{O presente nas escolas}

Nas escolas, o que está acontecendo?

Em capitais brasileiras, há psicanalistas que apontam casos de escolas nas quais em 20 crianças incluídas e com diagnóstico de TEA, 19 são tratadas pelo ABA.

É clara e já bem conhecida a tendência moderna de priorizar as técnicas de reeducação, supondose que a criança autista precisa ser adestrada, uma vez que está fora da vida subjetivada, digamos assim. Não há aposta em uma possibilidade de aprender, apenas na possibilidade de ser treinada.

As críticas ao comportamentalismo já estão cansando, e é preciso sair da polarização denunciada por Hochmann (2009) entre progressistas e canalhas. Muitos trabalhos de terapia comportamental, se feitos por humanistas, escapam do treinamento cego e da robotização.

Mas é preciso prosseguir na crítica daquilo em que o comportamentalismo peca essencialmente: as crianças autistas, escolarizadas pelos métodos comportamentais, perdem a chance de viver na escola a verdade de sua experiência, uma experiência peculiar e única. Perdem a chance de aprender a se dizer.

Para todas as crianças a escola deveria ser terapêutica, no sentido em que lhes oferece, pela mão do conhecimento, a chance de fazer alguma coisa com a angústia frente à sexualidade e à morte. Esses dois grandes parâmetros freudianos - a sexualidade e a morte - estão na base, em última análise, da verdade da experiência de uma criança.

Mas para as autistas essa oportunidade, trazida pelo conhecimento, não está ao alcance e isso por várias razões.

A primeira delas é que sua "angústia" não advém dos inevitáveis desencontros pulsionais e narcísicos com os outros, já que se trata de uma criança aquém do Édipo, aquém da sexualidade infantil no sentido freudiano. Hoje, a tragédia é não ter Édipo e não ser por ele atravessado.

Em segundo lugar, seu desassossego se origina no constante movimento e consequente desordenamento do mundo, que perturba seu desejo de imutabilidade, razão pela qual o objeto de conhecimento funciona, para elas, muito mais como um instrumento que a ajude a ordenar o mundo, ainda que de modo idiossincrático. Mas uma educação que levasse em conta esse desassossego e buscasse ao mesmo tempo apresentar o objeto de conhecimento como instrumento de subjetivação poderia "ensinar" uma criança autista a se dizer.

Não, as crianças autistas ou com traços autistas não estão aprendendo a dizer-se. Ainda no tempo presente, as crianças autistas que povoam a contemporaneidade em número crescente estão nas escolas, o que já representa uma diferença em relação ao passado. Mas o que aprendem nas escolas? Aprendem a se comportar e dali extraem o que há de mecânico no mundo. Algumas nem precisam ir à escola para, desde cedo, desfiar em tom monocórdico as letras em ordem alfabética e os números também ordenados. Outras já sabem tudo sobre tecnologia e rapidamente, logo que crescem um pouco, dominam a linguagem de um computador.

Não é, com poucas exceções, a escola do "dizer-se" que é apresentada para elas, mas a escola do "fazer". Sob o mandamento "inove-se", muitas escolas procuram modificar-se não tanto para 
atender ao principio democrático da educação para todos, mas para atender à demanda de inovação que a obriga a abandonar "seu suposto e ridicularizado anacronismo".

São duas as direções em que as crianças autistas poderiam ser escolarizadas: ou na dimensão da técnica, ou na dimensão da verdade de sua experiência.

Como será o mundo de amanhã quando houver bem mais adultos autistas do que temos hoje? Se a criança autista de hoje foi escolarizada pela técnica, quem será o adulto em que se transformará? E se foi escolarizada na direção de ser levada a dizer-se, em que adulto se transformará?

\section{O futuro?}

Se as coisas fossem simples assim, não seria difícil fazer um exercício de futurologia baseado na visão maniqueísta que hoje impera. Mas o problema é que a variedade é hoje muito maior do que se supõe. Assim como hoje se sabe que os gêneros podem ser em muito, mas muito maior número do que dois, ou três, ou cinco, assim os devires autistas podem ser os mais variados. Na clínica podemos encontrar uma criança que não desenha, está fixado na tecnologia, só quer saber das chaves USB, dos computadores e dos tablets, não liga muito para os amigos, mas ao mesmo tempo faz instalações incríveis que poderiam estar no MOMA, chora com um filme triste, e mostra ser capaz de fazer laços com os outros; podemos também encontrar uma criança diagnosticada com síndrome de Asperger que foi tratada desde os quatro anos com terapia comportamental e que conseguiu, com um falso self assim criado, ir à escola, aprender, chegar ao quarto ano. Apoiada nesse falso self, que a põe de pé, está tendo agora a chance de ser ouvida como sujeito. Muitas combinações, todas possíveis, levando a posições no mundo nas quais se pode ouvir ainda os ecos da presença de um sujeito.

Assim, o mundo caminha para o futuro, que só a Deus pertence.

De uma coisa, porém, sabemos. O sujeito, como o entendemos, corre o risco, o risco, sim, de vida. Risco de vida - e não de morte - , expressão genuína da língua portuguesa.

São, portanto, muitos os devires dos autistas. Mas haverá um ponto comum a todos eles: a supressão do sujeito. Pode-se prever unicamente isso: que em cada autista do futuro o sujeito freudiano, edípico, não estará lá.

\section{Há algo a ser feito com Isso?}

"Em um debate de ideias, a psicanálise sempre adotará a posição de ser contrária a todo discurso que suprime a função do sujeito" (Quinet, 2002, p. 36).

Mas se alguma ação precisa realizar-se, não será ela, de meu ponto de vista, em defesa da psicanálise. Tampouco minha linha de ação deverá centrar-se na defesa da instalação do discurso do analista nas escolas e nas instituições de tratamento. $\mathrm{O}$ discurso do analista serve, como disse 
Leguil (1958), para tratar das pessoas que sofrem com o discurso da Ciência e com a dessubjetivação do mundo, mas não para combater a Ciência.

Não é a psicanálise e tampouco o discurso do analista que precisam sair para o mundo. Não é a psicanálise, mas o psicanalista que precisa sair de sua posição entrincheirada em que se encontra, trincheira essa construída em nome da pureza da psicanálise.

O que faria o psicanalista, então, ao aventurar-se para fora do cômodo pique, para usar o chiste de C. Dunker? ${ }^{1}$

Restará ao psicanalista ser um testemunho vivo da experiência da psicanálise e da teoria do sujeito que lhe é intrínseca.

Pois como viver sem o sujeito, base inalienável do acionamento dos discursos e, portanto, do laço social? Poderemos viver sem o pacto societário, segregados cada um em seu canto e ilusoriamente acompanhados de nossas máquinas pessoais, nossos $P C$ s, nossos $P$ róprios $C$ asulos?

Munido de sua experiência, o psicanalista deverá operar como a resistência francesa durante a Segunda Guerra. Ele pode trabalhar como faziam os resistentes, que desviavam trens de crianças do curso a que estavam condenadas, levando-as para longe dos campos de concentração. A resistência Francesa tinha um duplo valor: o de salvar vidas e o de lutar contra a barbárie do nazismo. Ao desentricheirar-se, ao infiltrar-se nas linhas de combate das Políticas públicas, essa resistência do psicanalista terá também um duplo valor: dar aos autistas a chance de dizer-se, mas também resistir ao avanço da supressão do sujeito no mundo moderno.

Agora, não se trata de localizar a ameaça ao sujeito e a seu laço que a Ciência e a Medicina modernas representam. Trata-se de impedir a disseminação de formas de subjetivação robóticas, que ameaçam o laço civilizatório em nome de interesses que não são científicos, mas de mercado. Aqui não estou mais falando dos autistas. Estou defendendo uma posição política. Se um dia novas formas de vida humana vierem a se estabelecer, contra isso não podemos ou devemos fazer nada. Mas temos que opor forte resistência se elas advierem pela via da supressão odiosa e malintencionada da dignidade de uma pessoa, para quem seu bem mais precioso é seu desejo e o sujeito que nela habita.

\section{Referências}

Askofaré, S. (2009). Aspectos da segregação. A Peste, 1(2), 345-354. Recuperado de http://revistas.pucsp.br/index.php/apeste/article/view/6287/4621

Bourneville, D. M. (1893). Recherches cliniques et thérapeutiques sur l'épilepsie, l'hystérie, l'idiotie et l'hydrocéphalie: Compte-rendu du service des enfants idiots, épileptiques et arriérés de Bicêtre pendant l'année 1893. Disponível em https://bit.ly/35ib7v2.

1 Mencionado por C. Dunker em arguição da tese de Paula Fontana Fonseca na FEUSP (Psicanálise e Educação: inquietações políticas. Um debate a partir do encontro da psicanálise com a Educação Infantil no Brasil), em 31 de agosto de 2017. 
Catão, I., \& Vives, J.-M. (2011). Sobre a escolha do sujeito autista: voz e autismo. Estudos de Psicanalise, (36), 83-92. Disponível em https://bit.ly/2LYM5cP.

Dufour, D.-R. (2005). A arte de reduzir as cabeças. Sobre a nova servidão na sociedade ultraliberal (S. R. Felgueiras, trad.). Rio de Janeiro, RJ: Companhia de Freud.

Gonon, F. (2015). A psiquiatria biológica: uma bolha curativa? In A. Jerusalinsky (Org.), Dossiê autismo (pp. 198-229). São Paulo, SP: Langage.

Hochmann, J. (2009). Histoire de l'autisme. Paris: Odile Jacob.

Kupfer, M. C. M. (2000). Notas sobre o diagnóstico diferencial da psicose e do autismo na infância. Psicologia USP, 11(1), 85-105. https://dx.doi.org/10.1590/S0103-65642000000100006

Lacan, J. (1978) A instância da letra no inconsciente ou a razão desde Freud. In J. Lacan, Escritos (V. Ribeiro, trad., pp. 223-273). São Paulo, SP: Perspectiva. (Trabalho original publicado em 1957).

Lebrun, J.-P. (2004). Um mundo sem limite. Rio de Janeiro, RJ: Companhia de Freud.

Leguil, F. (1998). Formas do desencontro: segregação, solidão, amor. Curinga, 11, 5-44.

Meltzer, D.; Bremner, J.; Hoxster, S., \& Wittenberg, I. (1980). Explorations in autism. Londres: Karnac Books.

Pinel, P. (1801). Traité médico-philosophique sur l'aliénation mentale ou la manie. Paris: Richard, Caille e Ravier.

Quinet, A. (2002). A ciência psiquiátrica nos discursos da contemporaneidade. In A. Quinet, M. A. Peixoto, N. Viana, \& R. Lima (Orgs.), Psicanálise, capitalismo e cotidiano (pp. 31-39). Goiânia, GO: Germinal.

Séguin, E. (1846). Traitement moral, hygiène et éducation des idiots et autres enfants arriérés. Fonds numérisés Charcot. Paris: Baillière. Disponível em https://bit.ly/2pS2gjo.

Recebido em setembro/2019 - Aceito em dezembro/2019. 